of tea and coffee. Only three drugs are likely to be of use in preventing attacks-quinidine sulphate, digitalis, and procaine amide. Quinidine can no longer be used in this case, but digitalis is not necessarily contraindicated, since the patient may be extremely sensitive to, rather than intolerant of, the drug. A small maintenance dose of digitoxin or some other digitalis preparation to which she might be less sensitive deserves further trial. Although initial clinical evaluation of procaine amide indicated that it was ineffective in interrupting supraventricular paroxysmal tachycardia, subsequent trial has yielded more satisfactory results. The percentage of failures, however, is still high. The maintenance dose in this case would be $0.25 \mathrm{~g}$. three or four times daily. The drug is usually well tolerated, but toxic reactions have occurred and have included fatal agranulocytosis. Attacks may well occur, however, despite such preventive measures, and treatment should begin with the patient's own attempts to produce reflex vagal stimulation by manœuvres such as carotid sinus pressure, bilateral eyeball pressure, etc. These measures are successful in about 30 to $50 \%$ of cases. If they fail, cholinergic drugs may be tried. Methacholine chloride, 10 or $15 \mathrm{mg}$. subcutaneously, is the most effective. Vagal stimulation methods are most likely to succeed in nodal as opposed to atrial tachycardia. Digitalis is the drug of choice in attacks of the latter, but, since its use may be precluded in the case described, vigorous treatment with procaine amide might be necessary- 0.25 to $0.5 \mathrm{~g}$. twohourly by mouth to a total of four or five doses.

(3) In the absence of toxic reactions, quinidine therapy should be continued indefinitely if prolonged and distressing attacks of paroxysmal tachycardia recur when it is withdrawn.

\section{Female Orgasm and Conception}

Q.-Do the cervix, uterus, and Fallopian tubes during orgasm show any movements which may facilitate the penetration of semen? If so, does the absence of orgasm in the female reduce the chance of conception?

A.-It is generally supposed, though on very doubtful evidence, that the female internal genital organs do undergo muscular contractions during orgasm. Though it is certain that in some animals, such as the mare, "cervical insuck" of seminal fluid does occur during copulationwithout orgasm itself being involved-so that seminal plasma, as well as spermatozoa, can be found in the Fallopian tubes very soon after copulation, it is most improbable that there is anything comparable in women. In humans the ascent of spermatozoa through the cervix and uterus, and probably through the tubes also, is generally thought to be due to the unaided efforts of the spermatozoa themselves. Orgasm, it may be confidently stated, is not necessary for conception in women; indeed, many mothers have never experienced it. In so far as orgasm is likely to increase the flow of cervical mucus, it might well increase the chance of conception, but only by providing a more receptive medium for the ascent of spermatozoa through the cervical canal.

\section{Rabies in Cats}

Q. -What is the incidence of rabies in cats? What importance should be attached to a cat bite in the tropics?

A.-Rabies occurs in cats but is rare among them. Gordon Smith and Wells, ${ }^{1}$ in Malaya, refer to the dog as "the principal if not the sole vector" in that country. In the annual scientific report for 1952 of the Pasteur Institute, Coonoor, S. India, one cat is reported to have been found to have been rabid among 973 animals examined there. The incidence of the infection in cats will, of course, vary from region to region and no precise figures relating to its frequency are known.

The importance which should be attached to a cat bite in the tropics will depend on the circumstances in which the bite is received, and on the condition of the animal. If the animal bit as a result of being provoked little more significance need be attached to the bite than if it had been received in an area where rabies is not endemic. Rabies, however, should be suspected if the animal's behaviour has recently changed in any way and particularly if it has become increasingly affectionate or had spasms of the gullet. If there is a possibility of the animal having rabies it should be confined for a period of 10 days after biting. If it survives this period it can safely be assumed that the bitten person has not been infected. The indications for antirabic vaccine were discussed quite recently in "Any Questions?",

\section{REFERENCES}

${ }^{1}$ Gordon Smith, C. E., and Wells, C. W., Bulletin of the Institute of Medical Research, Kuala Lumpur, No. 8, 1955.

British Medical Journal, 1957, 1, 1018 .

\section{Tallqvist Haemoglobinometer}

Q.-How is the Tallqvist method of estimating haemoglobin carried out? Is it a useful and reliable method in circumstances where the cost of an M.R.C. photometer would not be justifiable?

A.-The Tallqvist haemoglobinometer consists of a book containing pieces of absorbent paper of standard size and thickness, and a series of colour standards printed on a card, each with a hole about $5 \mathrm{~mm}$. in diameter through its centre.

For use, a drop of blood is applied to the absorbent paper, and, as soon as its gloss has faded, the absorbent paper is backed with a second piece of absorbent paper (most conveniently by folding). The discoloured paper is then placed behind and in contact with the back surface of the printed standard and viewed through the holes until it is found to match one of the standards or to be darker than one and lighter than the next. The matching must be done by daylight, preferably by a north light coming from behind the observer, otherwise the hue of the standards will not match the blood at all. It is possible that the " north light" type of fluorescent lamp might be satisfactory, but I have not tried this.

The accuracy of the Tallqvist haemoglobinometer is about the same as that of the Haldane instrument, showing a standard deviation of about $10 \%$, so that not more than one result in twenty should be outside the range $\pm 20 \%$ from the true result. Provided the inquirer does not suffer from defective colour vision and he can work by daylight, the Tallqvist scale is quite useful for field work.

Correction.-The report of the meeting of the Section of Dermatology at Newcastle upon Tyne on Wednesday, July 17 (Journal, July 27, p. 225), should have stated that Dr. J. Ferguson Smith (Glasgow) was in the chair.

Collected Articles from the " British Medical Journal "

The following books are available through booksellers or from the Publishing Manager, B.M.A. House. Prices include postage.

Emergencies in General Practice (26s. 6d. inland; 26s. overseas).

Refresher Course for General Practitioners, Volumes 2 and 3

(26s. 6d. inland each, 26s. overseas).

Clinical Pathology in General Practice (22s. 3d. inland, 21s. 9d. overseas).

Any Questions?, Volumes 2 and 3 (8s. each).

All communications with regard to editorial business should be addressed to THE EDITOR, British Medical Journal, B.M.A. House, Tavistock SQUARE, LONDON, W.C.1 TELEPHONE: EUSTON, 4499. TELEGRAMS Aitiology, Westcent, London. ORIGINAL ARTICLES AND LETTERS forwarded for publication are understood to be offered to the British Medical Journal alone unless the contrary be stated.

Authors desiring REPRINTS should communicate with the Publishing Manager, B.M.A. House, Tavistock Square, W.C.1. on receipt of proofs. ADVERTISEMENTS should be addressed to the Advertisement Director B.M.A. House, Tavistock Square, London, W.C.1 (hours 9 a.m. to 5 p.m.) TELEPHONE: EUSTON 4499. TELEGRAMS: Britmedads, Westcent. London the Association TELEPHONE: EUSTON 4499. TELEGRAM: Medisecra. the Association TELEPHONE: EUSTON 4499. TELEGRAMS: Medisecra. B.M.A. SCOTTISH OFFICE: 7, Drumsheugh Gardens, Edinburgh. 